\title{
PERAN CIRI KEPRIBADIAN “BIG FIVE PERSONALITY” TERHADAP PENGGUNAAN ALAT PENGENDALIAN MANAJEMEN UNTUK MENINGKATKAN KINERJA AGEN PT PRUSOLID CITRA MANDIRI SURABAYA
}

\author{
Hartono Putra Ongkowijaya \\ Jurusan Akuntansi Fakultas Bisnis Ekonomika Universitas Surabaya \\ hartonoputra30@gmail.com
}

\begin{abstract}
Abstrak - penelitian ini bertujuan untuk memberikan gambaran secara nyata terkait dengan penerapan sistem pengendalian manajemen berdasarkan big five personality. Dari penelitian yang ada dapat dibuktikan bahwa dalam penerapan sistem pengendalian manjemen dengan disesuaikan dengan ciri kepribadian dari karyawan memberikan dampak yang positif dimana kinerja dari para karyawan tersebut dapat meningkat. SPM yang diterapkan akan dipengaruhi oleh ciri kepribadian dari karyawan dimana hal ini disebabkan oleh bargaining power yang lebih besar dari karyawan pada industri asuransi. Walaupun penerapannya berlawanan dengan teori yang ada dimana SPM ditentukan oleh pemimpin atau atasan, tetapi hasil dari penerapan ini dinilai cukup efektif terkait dengan peningkatan kinerja yang berdampak pada optimalisasi omset perusahaan.
\end{abstract}

Kata Kunci : Sistem pengendalian manajemen, lima ciri kepribadian, bargaining power, industri asuransi

Abstract - This research aims to provide an overview for real associated with implementation of management control systems based on the big five personality. From the research that there is a demonstrable that in the application of control systems managing with adapted to the personality traits of the employees gave a positive impact where the performance of the employees can be increased. MCS is applied will be influenced by the personality traits of the employees where this is due to the greater bargaining power of employees on the insurance industry. Although its application as opposed to the theory that there is where the MCS is determined by leader or supervisor, but the outcome of the application is evaluated as quite effective is associated with improved performance which impacted on the optimization of the company's turnover.

Keyword : Management control system, big five personality, bargaining power, insurance industries

\section{PENDAHULUAN}

Dalam rangka menciptakan kemajuan dan mencapai tujuannya, perusahaan dituntut agar dapat menghadapi berbagai masalah, terutama masalah internal perusahaan terkait dengan personel atau karyawan. Pihak manajemen 
harus mampu mengendalikan karyawannya dengan sedemikian rupa agar karyawannya dapat bekerja sesuai dengan visi misi dari perusahaan. Seperti pernyataan dari Merchant dan Van der Stede (2007), bahwa manusia adalah penyebab dari segala hal yang terjadi. Dari pernyataan tersebut mengungkapkan bahwa pusat dari sebuah organisasi atau badan usaha adalah pada manusia. Hal ini berlaku bagi segala bentuk usaha mulai baik perusahaan dagang, manufaktur dan tidak ketinggalan perusahaan jasa. Untuk mengatasi masalah ini dibutuhkan bentuk sistem pengendalian manajemen yang baik dan juga peran dari seorang pemimpin, mengingat bahwa setiap karyawan memiliki motif dan keinginan yang sangat spesifik dan terkadang berubah-ubah (Efferin dan Soeherman, 2010). Sistem Pengendalian Manajemen sangat penting diterapkan secara tepat agar setiap masing-masing individu dalam arti adalah anggota organisasi atau karyawan dengan harapan dan tujuan yang berbeda-beda dapat melakukan kegiatannya secara sealaras sesuai dengan tujuan organisasi atau visi dan misi dari organisasi.

Pada penelitian kali ini, peneliti menggunakan objek PT Prusolid Citra Mandiri Surabaya yang merupakan kantor agency dari PT Prudential Life Assurance yang bergerak di bidang jasa asuransi jiwa dan perencanaan keuangan. PT Prusolid Citra Mandiri Surabaya sendiri memiliki peran untuk melakukan tugas perekrutan agen baru atau biasa disebut tenaga pemasaran (salesforce), melakukan training agen, sampai ke tahap monitoring dari tiap agennya. Perekrutan di sini dimaksudkan tiap-tiap manajer unit bertugas untuk mencari agen baru, yang diharapkan menjadi tim atau unit dari manajer tersebut. Sedangkan tugas training dilakukan dengan sistem seminar-seminar, kelas pendalaman produk, kelas presentasi untuk melakukan pembekalan bagi tiap agen, agar siap melakukan penjualan produk asuransi sekaligus perencanaan keuangan bagi calon nasabahnya. Dan tugas terakhir adalah melakukan monitoring dan controlling pada tiap agen untuk menjaga konsistensi dari para agen tersebut akan komitmen yang hendak diberikan bagi dirinya sendiri maupun perusahaan. 
Kegiatan monitoring dan controlling merupakan kegiatan yang paling krusial dan yang paling penting diantara kegiatan yang lain di PT Prusolid Citra Mandiri Surabaya. Hal ini mengingat tidak adanya sistem kontrak dalam bisnis atau perusahaan ini pada tiap agen, artinya tidak ada peraturan yang dapat mengikat atau mengekang para agen, dengan kata lain para agen memiliki hak dan wewenang untuk melakukan tindakan di luar visi misi perusahaan (agency) atau bahkan sewaktu-waktu dapat keluar dari perusahaan tanpa ada prosedur yang resmi. Ditambah lagi, sistem kompensasi berupa komisi dan bukan gaji pokok, artinya agen tersebut akan memperoleh kompensasi ketika mereka memperolah nasabah atau client. Ini yang membuat industri asuransi memiliki ciri kas tersendiri dimana semua karyawan merupakan tenaga pemasaran atau agen itu sendiri, dan mereka merupakan aset yang paling penting bagi perusahaan. sehingga Hal ini akan menguatkan alasan bagi agen untuk semakin bebas melakukan aktivitasnya sehari-hari. Dengan demikian peran agen memiliki peran yang dominan, bahkan terkadang seorang pemimpin harus rela turun memberikan tutorial secara personal bila tidak mau agennya diambil oleh pihak perusahaan lain.

Manusia merupakan aspek sekaligus aset terpenting bagi sebuah organisasi (Efferin dan Soeherman, 2010). Terlebih lagi bagi PT Prusolid Citra Mandiri Surabaya. Hal ini disebabkan karena sumberdaya manusia dalam perusahaan ini merupakan sumber daya yang sangat utama atau bisa dikatakan merupakan ujung tombak dari perusahaan. Sifat dan kepribadian yang berbeda-beda dari tiap agen membuat sangat susah untuk melakukan pengendalian yang tepat dan sesuai sebagaimana dikatakan pada paragraf pertama, ditambah lagi tidak ada sistem dari pusat yang mengikat para agen membuat pihak manajemen dan juga sistem kompensasi berupa komisi tanpa ada gaji pokok, para leader (pemimpin) harus benar-benar memutar otak untuk menggunakan alat sistem pengendalian manajemen yang terdiri dari result control, action control, personel \& cultural control (Merchant dan Van der Stede, 2007)

Mengingat erat hubungannya dengan sifat dan kepribadian dari tiap-tiap agen, maka pemakaian alat sistem pengendalian manajemen harus disesuaikan 
dengan ciri kepribadian dari masing-masing agen atau tenaga pemasaran. Menurut Robbins (2003), ada 5 besar ciri kepribadian yang biasa digunakan dalam organisasi di dunia pekerjaan. Lima ciri kepribadian tersebut antara lain Extroversion, agreeableness, conscientionusness, emotional stability, openness to experience.

Menurut penelitian yang dilakukan Hebert dan Bradley (1997), tipe ciri kepribadian atau personal dari masing-masing karyawan atau perusahaan akan berdampak atau memberikan efek bagi kinerja. Efek tersebut dapat positif atau negatif sesuai dengan kepribadian yang dimiliki dan apa yang telah dikerjakan. Dan juga berdasarkan penelitian dari Arthur di Texas University, menyatakan bahwa dengan mengerti ciri kepribadian masing-masing karyawan akan mempermudah manajemen dalam memposisikan karyawannya di tempat yang benar, sehingga akan dapat meningkatkan kinerjanya.

Efek dari kepribadian sesorang terhadap kinerja yang baik atau buruk tidak terlepas dari peran sistem pengendalian manajemen yang diterapkan dari pemimpin ke karyawan. Sistem pengendalian manajemen sangat berguna untuk meminimalkan penyimpangan atas aspek perilaku dan hasil kinerja (Efferin dan Soeherman, 2010).

Berdasarkan hal-hal di atas, perlu dilakukan studi lebih mendalam mengenai bagaimana keterkaitan kepribadian agen (karyawan) dengan penetapan alat sistem pengendalian manajemen. Mengingat dalam penelitian yang ada sebelumnya lebih meniliti pada peran kepribadian dalam kinerja karyawan dalam hal penempatan kerja dari karyawan. Studi ini akan membahas lebih dalam tentang peran alat pengendallian yang diterapkan sesuai dengan ciri kepribadian karyawan sehingga nantinya tidak hanya dipandang dari segi penempatan kerja saja, melainkan dari berbagai aspek yang didukung dengan alat pengendalian manajemen. Topik dalam penelitian ini menjadi penting karena kompetisi di industri asuransi di Indonesia khususnya asuransi jiwa sangatlah ketat. Hal ini tidak terlepas dari agen atau tenaga pemasaran yang merupakan ujung tombak perusahaan. Mengingat jumlah agen yang banyak dan memiliki kepribadian yang 
berbeda-beda, maka dibutuhkan pengendalian yang sesuai agar mereka dapat memberikan hasil kinerja yang sesuai dengan harapan atau tujuan perusahaan.

\section{METODE PENELITIAN}

Studi yang dilakukan oleh penulis ini melibatkan secara langsung objek yang akan diteliti, agar penulis dapat mengetahui secara langsung bentuk pengendalian manajemen yang dilakukan, kemudian tipe-ciri kepribadian dari mayoritas agen yang berada di agency. Dalam mengumpulkan data untuk penelitian, penulis menggunakan 3 macam metode pengumpulan data yaitu : wawancara, observasi dan anilis dokumen untuk menganalisa dan menjawab tiaptiap main dan mini research question yang dibuat oleh peneliti. Proses pengambilan data yang dilakukan antara lain adalah Melakukan survei ke PT. Prusolid Citra Mandiri Surabaya dengan melakukan wawancara tatap muka langsung dengan salah satu direktur pada agency tersebut. Wawancara juga dilakukan kepada agen yang bersangkutan untuk memperoleh data lebih detail Alokasi yang diperlukan untuk melakukan wawancara kurang lebih 60 menit. Proses wawancara dilakukan dengan Semi structure interview dengan media catatan kecil. Kemudian kegiatan analisis dokumen juga dilakukan dengan menganalisis dokumen buku pedoman yang termuat dalam fomulir agen baru. Tahap terakhir adalah membandingkan hasil wawancara dengan hasil observasi serta dengan hasil dari analisis dokumen yang ada.

\section{HASIL DAN PEMBAHASAN}

Pada pembahasan ini akan dibahas tentang keterkaitan penerapan alat sistem pengendalian manajemen kepada para agen Prusolid dengan mempertimbangkan ciri kepribadian masing-masing. Pembahasan bab ini akan menajwab mini research question ke tiga terkait dengan bagaimana bentuk penerpan alat sistem pengendalian manajemen PT Prusolid Citra Mandiri Surabaya terkait hal tersebut, dan apakah pendekatan (alat kendali) yang dilakukan pada setiap agen asuransi pada PT Prusolid Citra Mandiri Surabaya adalah sama. 
Sebelum itu perlu diingat dalam kaitannya dengan alat SPM yang berlaku di Prusolid merupakan bentuk modifikasi dari SPM yang sebelumnya sudah ada dari pusat dalam arti dari PT Prudential Life Assurance di Jakarta. Pihak dari Prusolid yang telah mendapatkan jabatan manajer berhak memimpin agen dalam forum meeting untuk memaparkan SPM yang akan digunakan termasuk dalam kaitannya dengan ciri kperibadian dari si agen. Karena cukup banyak jabatan manajer di Prusolid membuat SPM ataupun kebijakan yang telah ditentukan pusat dapat diganti baik ditambahkan maupun dikurangi dengan penyesuaian dengan keadaan dari agen dalam unit masing-masing. Terutama dalam kaitannya dengan ciri kepribadian dari masing-masing agen tidak jarang beberapa aturan yang telah ada dari pusat dapat dimodifikasi sedemikian rupa agar menarik dan dapat diterima oleh masing-masing agen dengan kepribadian yang berbeda-beda. Salah satunya adalah peraturan tertulis pada perjanjian agen di awal termasuk salah satu bentuk pengendalian baik budaya maupun budaya yang tertulis secara formal.alan tetapi sesuai dengan penejesan pada subbab sebelumnya bahwa penerapannya beberapa ayat merupakan bentuk formalitas saja, akan tetapi tidak ada budaya untuk menjelaskan isi dari prosedur atau aturan tersebut pada agen baru, sehingga sampai agen teresebut dewasa, mereka tetap saja tidak tahu.

Hal ini tidak luput dari regulasi dari pusat yang memberikan kebebasan bagi pihak pemilik agency utnuk mengatur agency senderi. Walaupun terdapat regulasi tertulis yang resmi, akan tetapi karena budaya dari pemimpin akan tersalur ke agen dan akan turun menurun, sehingga karena orientasinya ingin memperoleh omset sebanyak-banyaknya tidak jarang aturan atau budaya pusat yang mengikat sering dimanipulasi atau modifikasi sedemikian rupa sehingga dapat menguntungkan pihak agen dari Prusolid. Dari hal tersebut terkadang ada beberapa sistem pengendalian manajemen yang ditetapkan kurang efektif terhadap beberapa agen dengan ciri kepribadian tertentu, ada juga yang cukup efektif.

Dalam pembahasan kali ini pengendalian yang dilakukan langsung dari atasan terhadap masing-masing agen melalui pendekatan interaktif menjadi metode SPM yang paling efektif di Prusolid. Maka dari itu dalam klasifikasinya, pengendalian manajemen melalui pendekatan pribadi dari atasan dipisah dari 
personel dan kendali budaya, dimana di dalam pengendalian personel dan budaya juga terdapat peran pendekatan secara personel dari atasan.

Berikut merupakan matriks hubungan antara ciri kepribadian dengan alat Sistem Pengendalian Manajemen pada PT Prusolid Citra Mandiri Surabaya.

Tabel 5.4

\section{Matriks Keterkaitan SPM dengan Big Five Personality dalam PT Prusolid Citra Mandiri Surabaya}

\begin{tabular}{|l|l|c|c|c|}
\hline SPM & $\begin{array}{l}\text { Result } \\
\text { Control }\end{array}$ & $\begin{array}{l}\text { Action } \\
\text { Control }\end{array}$ & $\begin{array}{l}\text { Cultural \& } \\
\text { Personel Control }\end{array}$ & $\begin{array}{l}\text { Pendekatan } \\
\text { Pribadi dari } \\
\text { atasan }\end{array}$ \\
\hline Extraversion & $\checkmark$ & $\checkmark$ & $\checkmark$ & $\checkmark$ \\
\hline Agreeableness & $\mathrm{X}$ & $\checkmark$ & $\checkmark$ & $\checkmark$ \\
\hline Conscientiousness & $\checkmark$ & $\checkmark$ & $\mathrm{X}$ & $\checkmark$ \\
\hline $\begin{array}{l}\text { Emotional } \\
\text { Stability }\end{array}$ & $\checkmark$ & $\checkmark$ & & $\checkmark$ \\
\hline $\begin{array}{l}\text { Openness to } \\
\text { Experience }\end{array}$ & $\checkmark$ & $\mathrm{X}$ & $\checkmark$ & \\
\hline
\end{tabular}

Keterangan :

$$
\begin{aligned}
& \checkmark=\text { Efektif } \\
& X=\text { Tidak efektif }
\end{aligned}
$$

Dari tabel matriks di atas dapat terlihat dengan sederhana peran dari sistem pengendalian manajemen terhadap agen dengan ciri kepribadian berdasarkan pendekatan teori big five personality factor, apakah memiliki peran secara efektif 
ataupun tidak. Efektif pada tabel di atas berkaitan dengan peningkatan omset dari masing-masing agen.

Berdasarkan Anthony dan Govindarajan (2007), sistem pengendalian manajemen merupakan proses dimana manajer mempengaruhi karyawan untuk mencapai tujuan organisasi melalui strategi yang diterapkan. Dari teori ini dapat terlihat bahwa proses penetapan dari alat kendali manajemen berpusat pada pihak manajemen dalam arti pihak yang memiliki kedudukan yang lebih tinggi yang dapat menentukan atau membuat SPM dalam suatu perusahaan. Pemimpin dinilai memiliki bargaining power (kemampuan untuk mempengaruhi) yang kuat sehingga dapat mempengaruhi dan mengatur bawahannya. Sehingga Pembuatan SPM yang dibuat seolah-olah hanya demi kepentingan dari pihak manajemen dan ditransformasikan keapda bawahan, bawahan mau tidak mau harus mengikuti sistem yang ada.

Hal ini bertentangan dengan penerapan SPM pada industri tertentu, seperti industri yang memiliki karyawan yang tidak memiliki kontrak secara formal dan resmi dari perusahaan atau bisa disebut karyawan lepas yang sewaktu-waktu dapat keluar dari perusahaan, dimana seperti yang tercantum pada teori SPM bahwa sumber daya manusia merupakan aset terpenting dalam perusahaan dan harus dikelola secara baik. Apakah yang terjadi apabila bawahan yang merupakan sumber daya utama pada suatu perusahaan dapat pergi seenaknya yang dimana hal ini desebabkan oleh struktur atau sistem organisasi dari perusahaan itu sendiri?. Industri atau perusahaan dengan sistem organisasi demikian membuat bawahan memiliki bargaining power yang seolah-olah lebih besar dari atasan atau pemimpin. Seperti halnya pada penelitian kali ini ditemukan bahwa perushaan dengan sistem organisasi demikian, bawahan cenderung dapat mempengaruhi atasan. Mempengaruhi dalam arti bawahan dapat memberikan pendapat yang dapat mengubah keputusan dari atasan tidak terkecuai penentuan SPM. Selain disebabkan karena sistem organisasi yang tidak adanya karyawan tetap, yang memungkinkan bawahan dapat seenaknya keluar dari perusahaan, faktor kekhawatiran dari atasan atau pemimpin itu sendiri akan perginya karyawan yang dianggap memiliki potensi yang luar biasa, menyebabkan tidak jarang seorang 
pemimpin harus dapat menyesuaikan dengan karakter atau kepribadian dari masing-masing bawahannya secara personal demi tercipta situasi kerja yang nyaman dan loyalitas dari bawahan.

Pemimpin pada bentuk industri seperti yang diungkapkan pada paragraf sebelumnya,cenderung akan menyesuaikan pada bawahannya untuk menentukan kebijakan perusahaan termasuk pembentukan sistem pengendalian manajemen. Dengan demikian diharapkan agar loyalitas dari bawahan akan meningkat disertai kenyamanan dalam bekerja sehingga produktivitas mereka akan meningkat pula. Dengan demikian teori bahwa Sistem Pengendalian Manajemen diterapkan dan diputuskan oleh atasan tidak seratus persen benar. Khususnya pada industri yang bawahan memiliki bargaining power yang lebih kuat daripada pemimpin atau atasan, di mana atasan akan dipaksa dengan kondisi yang ada agar dapat meyesuaikan dengan bawahannya demin tercipta loyalitas yang tinggi dari bawahan dan situasi yang nyaman untuk bekerja sehingga produktivitas yang merupakan tujuan dari perusahaan dapat tercapai dengan optimal.

\section{KESIMPULAN DAN SARAN}

Sistem Pengendalian Manajemen merupakan alat kendali yang dapat digunakan oleh organisasi dalam mengatur dan mengorganisir bawahannya agar bawahannya dapat bertindak atau beraktivitas sesuai dengan tujuan organisasi. Beberapa alat kendali manajemen yang dapat digunakan antara lain adalah pengendalian hasil, pengendalian tindakan, pengendalian personel dan budaya serta pengendalian interaktif.

Mengingat bentuk organisasi dari sebuah agency asuransi memiliki sistem yang sedikikt unik dimana memiliki jumlah agen yang banyak dan memiliki ciri kepribadian yang berbeda-beda membuat para leader atau pemimpin harus bisa sebaik mungkin mengatur atau mengorganisir sedemikian rupa agar agen dibawah unit atau grup masing-masing mencapai tujuan organisasi.

Melihat dari penelitian ini maka dapat disimpulkan bahwa ciri kerpibadian agen akan menentukan kesesuaian dengan penentapan alat kendali manajemen demi meningkatkan kinerja dari masing-masing agen dengan harapan tujuan 
organisasi tercapai mengingat bawahan memiliki bargaining power yang lebih kuat dibanding dengan atasan. Apabila SPM yang ditentukan telah sesuai maka dalam bekerja agen akan merasa nyaman sehingga tidak menutup kemungkinan loyalitas mereka akan meningkat, apabila loyalitas telah meningkat dan kenyamanan kerja telah tercipta, hal ini dapat berdampak pada produktivitas atau kinerja mereka dalam melakukan penjualan polis asuransi, dengan demikian omset mereka akan meningkat, tentu hal ini akan berdampak bagi kenaikan porduktivitas yang merupakan tujuan utama dari perusahaan.

\section{DAFTAR PUSTAKA}

Anthony, R. dan V. Govindarajan. 2007. Management Control System, $12^{\text {th }} \mathrm{ed}$. New York: McGraw-Hill.

Bradley, J.H., F. J. Hebert. 1997. The Effect of Personality Type on Team Performance. Journal of Management Development Vol. 16 Iss: 5 pp. 337353.

Cramer, K.M. dan E. Imaike. 2002. Personality, Blood Type, and The Five-factor Model. Personality and Individual Differences 32 621-626.

Efferin, S. dan Bonnie Soeherman. 2010. Seni Perang Sun Zi dan Sistem Pengendalian Manajemen: Filosofi dan Aplikasi. Jakarta: PT Gramedia.

Ingarianti, Tri Muji. 2012. Hubungan antara Kepribadian (The Big Five Factor Personality) dengan Organizational Citizenship Behavior pada Karyawan. Fakultas Psikologi Universitas Muhammadiyah Malang.

Luthans, Fred. 2006. Perilaku Organisasi Edisi 10. Yogyakarta: Andi Yogyakarta.

Merchant, K.A., W. A. Van der Stede. 2007. Management Control Systems: Performance Measurement, Evaluation and Incentives. London: PrenticeHall.

Robbins, Stephen P. 2004. Perilaku Organisasi 9th voll. Jakarta: Indeks.

Robbins, Stephen P. 2001. Organizational Behavior. Upper Saddle River: Prentice-Hall.

Winfred, A., et al. 2001. Personality Testing in Employment Settings: Problems and Issues in The Application of Typical Selection Practices. Personnel Review Vol. 30 No 06, pp. 667-676. 